\title{
Article choice in children with High Functioning Autism (HFA) and in children with Specific Language Impairment (SLI)
}

\author{
Jeannette Schaeffer, Merel van Witteloostuijn \\ and Doatske de Haan
}

University of Amsterdam

This study reports on the choice between a definite and an indefinite article by children with High Functioning Autism (HFA) and children with Specific Language Impairment (SLI). We carried out an elicited production task with 16 Dutch-speaking non-grammatically impaired children with HFA aged 6-13, 16 age-matched Dutch-speaking children with SLI, and 16 typically developing (TD) age controls. The results in the indefinite conditions reveal virtually no errors across groups. However, in the definite condition the HFA group, but NOT the SLI group, incorrectly produces indefinite articles significantly more often than the TD group. A more detailed analysis shows that $38 \%(6 / 16)$ of the children with HFA vs. $13 \%$ (2/16) of the children with SLI regularly produce indefinite articles in definite contexts. We propose that these children do not always calculate the additional (pragmatic) meaning of indefinites derived by scalar implicature (Horn 2006). Furthermore, development by age in the SLI group, but NOT in the HFA group, suggests that the failure to draw a scalar implicature is more persistent in children with HFA than in children with SLI. Concluding, our results show that non-grammatically impaired children with HFA are more prone to pragmatic impairments than children with SLI, suggesting a dissociation between grammar and pragmatics.

Keywords: Article choice, definiteness, autism, SLI, Scalar Implicature

\section{Introduction}

The choice between a definite (the) and an indefinite ( $a$ ) article has been the topic of much research in the fields of monolingual L1 (Maratsos 1976; Karmiloff-Smith 1979; Zehler \& Brewer 1982; Schafer \& de Villiers 2000; Schaeffer \& Matthewson 
2005; van Hout, Harrigan \& de Villiers 2010, among others) and L2 acquisition (Ionin \& Wexler 2003; Ionin, Ko \& Wexler 2004; Ionin, Zubizarreta \& Maldonado 2008; Zdorenko \& Paradis 2008, among others). However, it has rarely been studied in the language acquisition of impaired populations (but cf. Polite, Leonard \& Roberts' 2011 study and Chondrogianni \& Marinis' study (in press) on English SLI). The present study investigates the choice of a definite versus an indefinite article in various (in)definite (non-)referential contexts in children with High Functioning Autism (HFA) as compared to children with Specific Language Impairment (SLI). The rationale behind the comparison of these two impaired populations is as follows: As argued by Stalnaker $(1974,1978)$ and Heim (1982) among many others, the choice between a definite and an indefinite article as in (1) and (2) depends on knowledge of speaker/hearer assumptions (to be elaborated on in Section 2) and can thus be assumed to be part of pragmatics.

(1) Dit is een verhaal over een (bepaalde) jongen.

De jongen woonde in een groot kasteel.

'This is a story about a (certain) boy.'

The boy lived in a big castle'

(2) Ik heb zin om een boek te lezen (wat voor boek dan ook).

'I feel like reading a book (whatever book it may be).'

The first sentence in (1) contains the noun jongen ('boy'), which is introduced by the speaker while its referent is still unknown to the hearer. Therefore, the indefinite article een ('a') is chosen. In the second sentence, the referent of jongen is known to both the speaker and the hearer, yielding the choice of the definite article $d e$ ('the'). In (2), the referent of the noun boek ('book') is unknown to both speaker and hearer, resulting in the choice for an indefinite article as well.

Typical characteristics of children with HFA include abnormal communication and deviant pragmatics (see Baron-Cohen 1988; Frith 1989 and TagerFlusberg 1989 for reviews). In contrast, although all children with SLI show severe grammatical impairments, there are SLI sub-groups showing intact pragmatics (van der Lely 1998; Friedmann \& Novogrodsky 2008, 2011). If article choice is a pragmatic phenomenon, and children with HFA are pragmatically impaired, one would expect that they would make errors regarding article choice. In contrast, article choice errors are not expected to be a key characteristic of children with grammatical SLI. Confirmation of these predictions (even for sub-groups of HFA and SLI) would provide evidence for the linguistic-theoretical hypothesis that pragmatics constitutes a separate language component that can be impaired independently of other language components, such as morphosyntax (which is impaired in individuals with SLI). In terms of clinical linguistics it would show 
that the main language problem for children with HFA resides in the pragmatic component of language, while this is not a primary impairment in SLI. Yet, we do not exclude the possibility that it could be a secondary impairment in SLI.

In the next section we describe the article choice phenomenon in some more detail (2.1), followed by an overview of relevant L1 acquisition studies showing that monolingual children often overgenerate the definite article in indefinite contexts, but also incorrectly interpret indefinite articles as having a determined referent (known to both speaker and hearer) (2.2). This section also contains a brief overview of the main characteristics of HFA and SLI (2.3). In Section 3 we present our hypotheses and the predictions for HFA and SLI. The methods to test these are described in Section 4. The results are presented and discussed in Section 5, followed by the conclusion in Section 6 .

\section{Background}

\subsection{Article choice in adult language}

In the literature, definites are characterized by 'uniqueness' and by 'familiarity'. Uniqueness theories focus on the semantic requirement that the referent of the definite noun phrase be uniquely identifiable to the addressee (Russell 1905; Hawkins 1991, among many others). Familiarity theories emphasize the pragmatic requirement that the referent be familiar to speaker and hearer. Both theories encounter some empirical problems (for an overview see Abbott 1999, 2003), but it goes beyond the scope of this paper to discuss these here. In this study we focus on the pragmatic requirement of familiarity for definites, which is further explained below.

Beliefs that are shared by all interlocutors in a discourse are said to be in the so-called COMmON GROund of the discourse (Stalnaker 1974, 1978; Heim 1982, amongst others). As argued by Heim (1982), the definite article the places a requirement on the content of the common ground at the time of utterance. Speaking informally, the use of [the $\mathrm{N}$ ] requires that the existence of a (unique) referent corresponding to that nominal phrase be part of the shared assumptions between speaker and hearer at the time of utterance. If the existence of such a referent is not part of the shared assumptions between speaker and hearer, infelicity results, as illustrated in (3):

(3) A: I dreamed about the giraffe last night!

B: What giraffe? 
One way to become part of the common ground was illustrated in (1): The existence of a unique entity corresponding to the definite noun phrase de jongen ('the boy') is part of the shared assumptions between speaker and hearer, i.e. the common ground, because it was established in the previous discourse, namely by the indefinite noun phrase een jongen ('a boy').

Sometimes the speaker but not the hearer assumes the existence of an entity corresponding to the noun phrase. For example, in the first sentence in (1) above, the speaker has grounds for an existential assertion about boys, while the hearer does not. As we saw in example (2) above, it is also possible for neither the speaker nor the hearer to have grounds for an existential assertion.

Inspired by Schaeffer \& Matthewson (2005), we propose the schema in (4) for the canonical realizations of the three possible assumption states in the Dutch adult article system ('Assumed by $\mathrm{X}$ ' is shorthand for ' $\mathrm{X}$ has grounds for an existential assertion'):

(4) The Dutch adult article system

\begin{tabular}{llll}
\hline A & Assumed by speaker and hearer & Part of common ground & de \\
B & Assumed by speaker only & Not part of common ground & een \\
C & Assumed by neither speaker nor hearer & Not part of common ground & een \\
\hline
\end{tabular}

\subsection{Previous L1 studies on article choice}

Cross-linguistic research on the acquisition of article choice shows that young monolingual children acquiring a two-article language system based on definiteness often use definite articles where adults would use an indefinite (Maratsos 1976; Karmiloff-Smith 1979; Zehler \& Brewer 1982; Schaeffer \& Matthewson 2005; van Hout, Harrigan \& de Villiers 2010). An example is given in (5):

(5) Situation: Picture of Mickey Mouse who just finished drawing a house (visible to child, but not to experimenter).

Exp: What did Mickey Mouse just do?

Child: He drew the house. (Schaeffer \& Matthewson 2005)

Schaeffer \& Matthewson (2005) explain this phenomenon by the lack of a pragmatic concept, as formulated in (6):

(6) Concept-of-Non-Shared-Assumptions (CNSA) Speaker and hearer assumptions are always independent

If the CNSA is absent, speaker and hearer assumptions are not always independent, implying that there are situations in which the speaker automatically attributes her/his own assumptions to the hearer. The CNSA expresses an obligation 
for the speaker to consider the hearer's assumptions as a separate entity and therefore as something that is in principle different from the speaker's assumptions. However, in certain cases, speaker and hearer assumptions may coincide. This description of the CNSA may remind the reader of Theory of Mind (Premack \& Woodruff 1978). Although we are hesitant to fully equate the CNSA to Theory of Mind, we do acknowledge that the two are probably related, and suggest that the CNSA may be a component or a pre-cursor of Theory of Mind.

One of the effects of lacking the CNSA concerns the distinction of articles. As illustrated in the schema in (4), in adult Dutch (or English, for that matter), the semantics of articles mandates the grouping together of contexts $\mathrm{B}$ and $\mathrm{C}$ (as opposed to A). If a speaker attributes her own (speaker-) beliefs to the hearer, she will not distinguish environment $B$ (believed by speaker only) from environment A (believed by speaker and hearer). In other words, environment B becomes environment A. In these cases, the speaker will use the article appropriate for environment A, which is the in English, or de in Dutch. Thus, in the cases in which the speaker does not distinguish speaker and hearer beliefs, she groups together environment $\mathrm{A}$ and $\mathrm{B}$, as opposed to $\mathrm{C}$, as illustrated in (7):

(7) Possible article choice in child language

\begin{tabular}{lll}
\hline $\mathrm{A} / \mathrm{B}$ & Assumed by speaker (and therefore by hearer) & the \\
$\mathrm{C}$ & Not assumed by speaker (and therefore not by hearer) & $a$ \\
\hline
\end{tabular}

The chart in (7) shows that the lack of the CNSA sometimes yields a one-to-one mapping between speaker beliefs and the form of the article (rather than between common ground and the form of the article). If the referent is assumed to exist by the speaker, the is used; if no referent is assumed to exist by the speaker, $a$ is used. ${ }^{1}$

Schaeffer \& Matthewson (2005) show that English-acquiring children up until age 4 overgenerate the definite article in indefinite referential contexts, and claim that this is due to the lack of the CNSA. Once the CNSA is acquired (around the age of 3 or 4 ), contexts $A$ and $B$ are distinguished, and the overgeneration of the definite article disappears. Research on the acquisition of subjects provides further evidence for the hypothesis that TD children initially lack the CNSA (Gordishevsky \& Avrutin 2004; Westergaard 2008).

Casting their account of the overgeneration of the in indefinite contexts in a framework of (bi-directional) Optimality Theory developed by Hendriks, de Hoop, Krämer, de Swart \& Zwarts (2010), van Hout et al. (2010) argue that initially, the two constraints that determine reference for definite and for indefinite articles are unranked, resulting in the production of $a$ and the at chance level in indefinite contexts (ages: 3;7-5;3, mean age 4;6). Language learners must discover that Determined Reference ranks highest, and applies in interpretation only, 
and that Avoid Indefinites ranks lowest, and applies in production only. What is not clear from van Hout et al's (2010) OT account is whether the children's immaturity regarding the overgeneration of the lies in the area of grammar, or in the area of pragmatics, and therefore it does not make straightforward predictions for children with SLI or HFA.

Interestingly, van Hout et al. (2010) also found non-adultlike interpretations of the indefinite article $a$ in the same children (3;7-5;3, mean age 4;6). Comprehension of the indefinite article was tested with a so-called 'referent-selection paradigm. Children were presented with pictures and a story and asked to move an item in the picture to match the story. An example of an item testing the comprehension of indefinite article is presented in (8).

(8) "John sees his teacher with a piece of cake.

He asks her if he can have a piece of cake."

Target: a different piece

Results indicate that children incorrectly interpret $a$ as referring to the unique referent (the piece of cake held by the teacher) $59 \%$ of the time.

Van Hout et al. (2010) explain this non-adultlike interpretation of indefinites by the failure to draw scalar implicatures. These are implicitly communicated propositions linked to relatively weak terms (consider, for example, how some pragmatically implies not all) (Pouscoulous, Noveck, Politzer \& Bastide 2007). The general consensus is that the weaker term (e.g. the quantifier some), while logically/semantically compatible with a stronger term from the same scale (e.g. all), prompts the pragmatic inference because the speaker did not use the stronger term (Horn 1989; Carston 1998; Levinson 2000; Chierchia 2004; Wilson \& Sperber 2004). Hawkins (1991) and Horn (2006) propose that adults draw a scalar implicature when they interpret indefinite NPs. They argue that the and $a$ provide a contrastive set, in which the is the logically stronger and most informative member of the pair: $\langle a$, the $\rangle$. Indefinite interpretations are then analyzed as implicatures that result from not using the definite article in corresponding expressions (Hawkins 1991:417). If children fail to draw a scalar implicature when they interpret indefinite NPs, as in van Hout et al's (2010) comprehension study, they arbitrarily choose between a determined referent meaning and a non-determined referent meaning when they hear an indefinite.

\subsection{High Functioning Autism and Specific Language Impairment}

Turning now to impairments, the autism spectrum contains various forms of autism, with Autistic Disorder at the more severe end of the spectrum, through the less severe Asperger's Disorder and Pervasive Developmental Disorder-Not 
Otherwise Specified (PDD-NOS) at the other end (Taylor, McPheeters, Sathe, Dove, Veenstra-Van der Weele 2012). In this study we concentrate on children with Autism Spectrum Disorder at the least severe end of the spectrum, i.e. High Functioning Autism (HFA). These children experience difficulties in the social use of language and are claimed to be pragmatically impaired, just like children with more severe autism spectrum disorders (see Baron-Cohen 1988; Frith 1989; TagerFlusberg 1989; Eigsti, de Marchena, Schuh \& Kelley 2011; Loukusa \& Moilanen 2009 for reviews). Although grammar has been reported to be mostly spared in this population (Boucher 2009), recent research has shown that some children with autism also have grammatical impairments (Perovic, Modyanova \& Wexler 2013a, 2013b). However, researchers agree that the main language impairment of children with autism is pragmatic in nature.

In contrast, children with Specific Language Impairment (SLI) are characterized by a significant limitation in language ability, yet, they have no hearing impairments, no neurological damage, and a normal non-verbal IQ of 85 or higher (Bishop 1997; Leonard 1998, among others). Like HFA, SLI is a 'congenital' disorder that often runs in families. This suggests that it has a genetic basis (e.g. Tallal, Ross \& Curtiss 1989; Tomblin 1989; Rice 1996). One of the exclusionary criteria for the diagnosis of SLI is that there are no symptoms of impaired reciprocal social interaction or restriction of activities (Leonard 1998). Although several researchers argue that children with (grammatical) SLI merely have a morphosyntactic deficit (van der Lely 1998; van der Lely \& Stollwerck 1997; Friedmann \& Novogrodsky 2008) and have virtually no pragmatic or cognitive problems, there are also studies that show correlations between certain executive functions and language performance in children with SLI (Henry, Messer \& Nash 2012). However, most researchers agree that the primary and most severe deficit of children with SLI lies in their grammatical system.

\section{Hypotheses and predictions}

Taking the explanations of previous acquisition studies for the errors young children make regarding article choice as a starting point, we now present two sets of hypotheses and predictions for Dutch-acquiring children with HFA on the one hand, and for Dutch-acquiring children with SLI on the other hand.

Recall that Schaeffer \& Matthewson (2005) argue that young children (up to the age of 3 / 4) overgenerate definite articles in indefinite contexts because of the lack of the pragmatic Concept of Non-Shared Assumptions (CNSA). We follow Schaeffer \& Matthewson in hypothesizing that for correct indefinite article choice, it is necessary to have an intact CNSA. Furthermore, we hypothesize that 
children with HFA have impaired pragmatics, and possibly lack the CNSA. In contrast, children with SLI are hypothesized to have the same pragmatics as their agemates, and therefore to have age-mate-like knowledge of the pragmatic CNSA.

Furthermore, as described in Section 2.2, van Hout et al. (2010) propose failure to calculate a scalar implicature to account for the non-adultlike interpretation of indefinite articles in young children. Although van Hout et al. consider the scalar implicature for definiteness only in terms of comprehension, we assume that scalar implicatures apply in production as well. For the correct production of definite articles then, we hypothesize that it is necessary to calculate a scalar implicature. When a speaker uses an indefinite article, s/he implicates that the use of a definite article would be too strong, i.e. she takes into account the scalar implicature the hearer will draw. Notice that this is a one-way reasoning, starting from the weaker member of the scale: When the weaker member of the scale (in our case $a$ ) is used, this implicates that the stronger member (in our case the) is too strong. Yet, no scalar implicature is drawn if the stronger member of the scale is used (see also Hawkins 1991; Horn 2006). Thus, absence of scalar implicature calculation has repercussions for the choice of indefinite articles, but not for the choice of definite articles.

Assuming that children with HFA have impaired pragmatics, we hypothesize that they fail to calculate scalar implicatures, resulting in the production of indefinite articles in definite contexts: If the implicature that choosing $a$ means that the is too strong is absent, $a$ can be used in all contexts. In contrast, absence of this implicature does not predict overgeneration of the in indefinite contexts, since the choice for the does not involve scalar implicature calculation to begin with.

In contrast, children with SLI are hypothesized to have no particularly severe difficulties with pragmatics, and should therefore have no problems calculating scalar implicatures.

Nonetheless, as mentioned in Section 2.3, SLI and HFA populations can be quite heterogeneous in terms of their developmental impairments. We therefore formulate our predictions for at least a subgroup of children with HFA, and at least a subgroup of children with SLI.

The predictions that follow from these hypotheses are listed in (9) for children with HFA, and in (10) for children with SLI:

(9) Predictions for (a subgroup of) children with HFA regarding article choice

a. Children with HFA overuse de/het in referential indefinite contexts because they lack CNSA

b. Children with HFA overuse een in definite contexts because they fail to calculate scalar implicature 
(10) Predictions for (a subgroup of) children with SLI regarding article choice

c. Children with SLI ( $>$ age 4) do not overuse de/het in referential indefinite contexts because they do not lack CNSA

d. Children with SLI ( > age 4) do not overuse een in definite contexts because they can calculate scalar implicature

\section{Methods}

\subsection{Participants}

In order to test these predictions we recruited 16 children with HFA, aged 5-13 (mean 9.13; SD 2.28) through Dutch organizations for autism, autism groups on Facebook and personal contacts. Furthermore, 16 children with SLI aged 6-13 (mean 8.94, SD 2.29) were selected from special schools for children with speech and language problems in The Netherlands. Children with an IQ $<85$ and/or officially diagnosed with any additional disorder (such as autism in the SLI group or language impairment in the HFA group) or $\mathrm{AD}(\mathrm{H}) \mathrm{D})$ were not included. Nevertheless, we do not exclude the existence of comorbidity with other developmental disorders in both the SLI and the HFA group. 16 typically developing (TD) children aged 6-13 (mean 9.25; SD 2.21) served as a control group. All child participants were individually matched with respect to age and gender. Agenormalized scores of expressive and receptive linguistic ability were obtained from the Dutch version of the Clinical Evaluation of Language Fundamentals (CELF-4NL) (Semel, Wiig, Secord \& Kort 2008). Whereas the SLI group performed far below the norm score of the 50th percentile (mean 7.35, SD 7.14), the HFA and TD groups performed around or above the norm score (HFA mean 55.33, SD 30.44, TD mean 78.04, SD 20.76). Furthermore, Non-Word Repetition (Rispens \& Baker 2012) scores obtained from each group confirm the diagnostic value of this test for children with SLI: The SLI group's NWR score was $32.2 \%$, vs. $59.7 \%$ for the HFA group, and $68.6 \%$ for the TD group. Additionally, parents of all HFA participants completed the Dutch version of the Children's Communication Checklist (CCC2-NL) (Geurts 2007). One of the main goals of this checklist is to give an impression of pragmatic abilities, as measured by the 'pragmatic score. This score is given as a percentile and ranges from 0 (very good pragmatic skills) to 100 (very poor pragmatic skills). The HFA group's scores between the 80th and 99th percentile (mean 96.6, .SD 5.1) indicate their very weak pragmatic abilities. ${ }^{2}$ Finally, 7 adult mother tongue speakers of Dutch aged 42-56 (mean 49.71; SD 4.46) were tested to ensure the psychological reality of the expected target responses. 


\subsection{Materials and procedure}

Our materials consist of an Elicited Production Task (cf. Crain \& Thornton 2000) in which the participants are asked to describe an event in a picture or short video clip displayed on a computer screen to an experimenter who cannot see the screen while a second experimenter is sitting next to the participant. Following Schaeffer \& Matthewson's (2005) schema on definiteness and referentiality as presented in Section 2.1, three different conditions are distinguished, namely (i) definite (6 test items), (ii) indefinite-referential (6 test items), and (iii) indefinite-non-referential (6 test items). ${ }^{3}$ Furthermore, the experiment contains 18 fillers, eliciting utterances with a scrambled or a non-scrambled object (which were later used for a different study). The conditions are schematized in (11), and sample scenarios of each condition are provided in (12a through c).

(11) Experimental conditions Elicited Production Task on Article Choice

\begin{tabular}{lc}
\hline Condition & Number of items \\
\hline 1-Definite & 6 \\
2- Indefinite referential & 6 \\
3 - Indefinite non-referential & 6 \\
Total experimental items & 18 \\
Fillers & 18 \\
\hline
\end{tabular}

(12) a. Sample scenario Definite condition

Situation: Picture of a puppet with a ball (visible to participant, but not to experimenter).

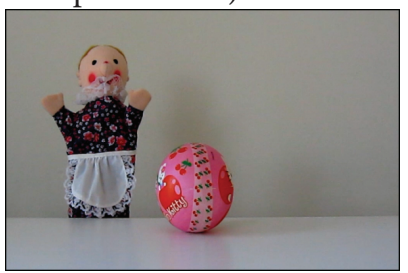

Exp: Hey, who do you see in the picture?

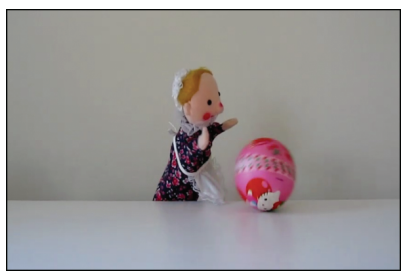

Exp: What did ${ }^{*}$ name ${ }^{\star}$ just do?

Participant: ${ }^{\star N a m e} e^{\star}$ (Name of the puppet) Target: She rolled the ball. Exp: What else do you see?

Participant: A ball!

Situation: Movie of puppet rolling the ball. 
b. Sample scenario Indefinite Referential condition

Situation: Picture of Dora who has drawn a heart (visible to participant, but not to experimenter).

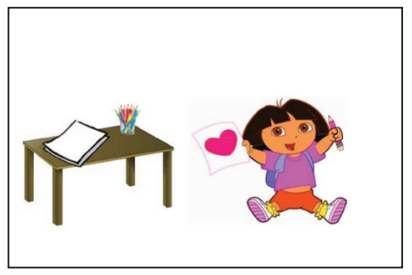

Exp: Hey, who do you see in the picture?

Participant: Dora!

Exp: And what did Dora just do?

Target: She drew a heart.

c. Sample scenario Indefinite Non-referential condition

Situation: Picture of Big Bird thinking with a pencil in his hand (visible to participant, but not to experimenter).

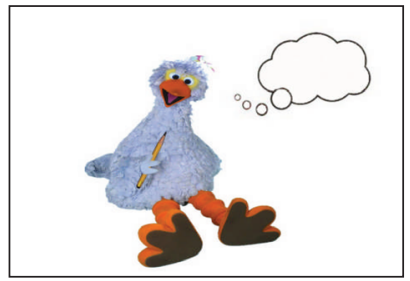

Exp: Hey, who do you see in the picture?

Participant: Big Bird!

Exp 2: Big Bird says: "Oh, I am so bored, I don't know what to do. Oh, you know what? I'll go to the forest and draw something!" Exp: What do you think Big Bird is going to do in the forest? Target: He is going to draw a tree.

\section{Results and discussion}

In this section, we first present and discuss our results on the two indefinite conditions against the background of our predictions, followed by a presentation and discussion of the results on the definite condition.

Our results on the indefinite non-referential condition and the indefinite referential condition are given in Figures 1 and 2, respectively: 


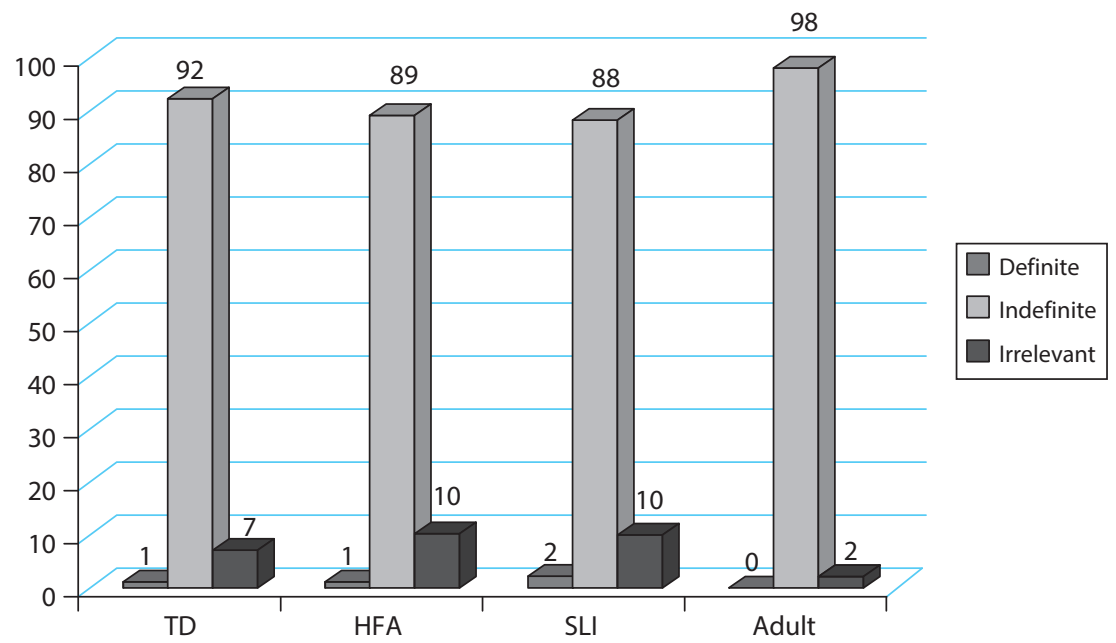

Figure 1. Indefinite non-referential condition: Proportions of definite (incorrect), indefinite (correct), and irrelevant responses

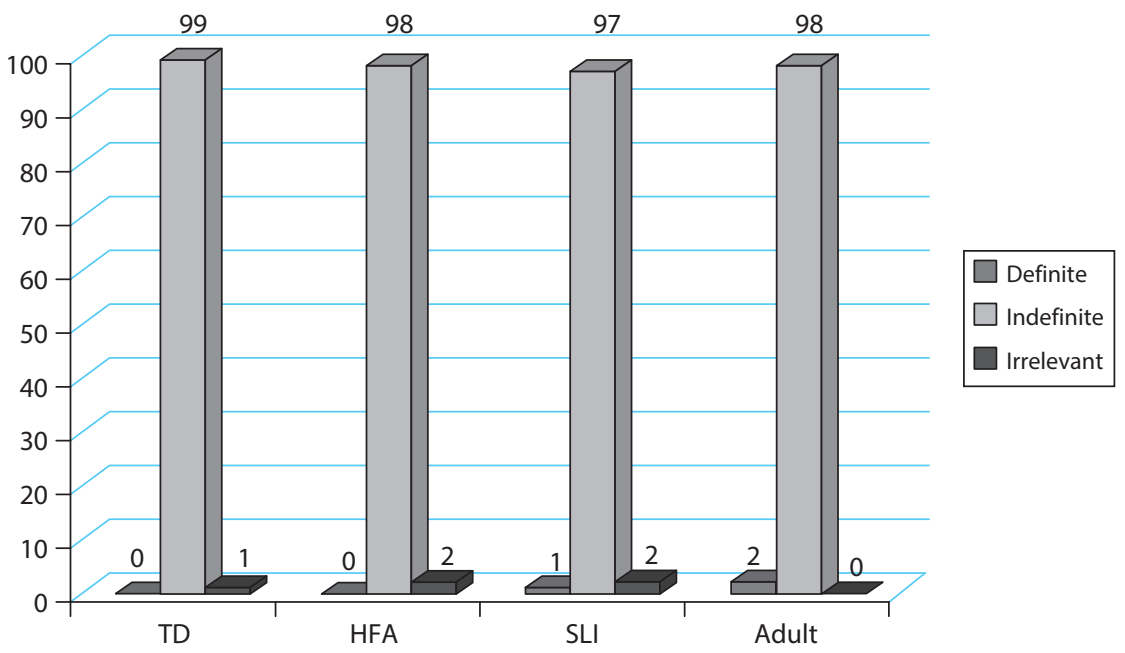

Figure 2. Indefinite referential condition: Proportions of definite (incorrect), indefinite (correct), and irrelevant responses

The tall bars in Figures 1 and 2 show that all children and adults overwhelmingly choose to produce the target indefinite article in both indefinite conditions. Kruskall-Walis tests show that none of the differences between participant groups or response types are statistically significant.

Firstly, the results on the indefinite non-referential condition (Figure 1) show that none of the participants has any difficulty producing indefinite $a$ in contexts in which neither the speaker nor the hearer has grounds for an existential assertion 
regarding the referent of the noun. As neither lack of the CNSA nor failure to draw a scalar implicature (both pragmatics) predicts such a result, it is not surprising that even our HFA group performs well on this condition. Importantly, it indicates that article choice in SLI or HFA is not random and that even our impaired participants adhere to some underlying system guiding article choice. Our finding that the children with SLI perform well on the indefinite non-referential condition is corroborated by a recent study by Chondrogianni \& Marinis (in press), who report good performance in their indefinite non-referential predicational context by an English-speaking group of 24 children with SLI with a mean age of 7;5.

Secondly, recall our prediction that children with HFA overuse de/het in indefinite referential contexts because they lack the CNSA. As the results on the indefinite referential condition in Figure 2 above demonstrate, this prediction is not borne out: None of the participants, including the children with HFA, overgenerate the definite article de/het in this condition. Nevertheless, the results in Figure 2 do confirm our prediction that children with SLI (who are hypothesized to have the CNSA) do not overgenerate de/het in indefinite referential contexts. These results suggest that neither the children with SLI nor the children with HFA lack the CNSA. In other words, although the children with HFA tested in our experiment may be pragmatically impaired, the part of pragmatics that is responsible for their knowledge that speaker and hearer assumptions are always independent (CNSA) seems to be intact.

In Section 2.2, we discussed the potential connection between the CNSA and Theory of Mind (ToM). Therefore, we also conducted a non-verbal False Belief (FB) task (Colle, Baron-Cohen \& Hill 2007) with all our participants. Interestingly, the children with HFA were good at this task and even outperformed both the TD children and the children with SLI (HFA: $81.4 \%$ correct, TD: $62.6 \%$ correct, and SLI: $64.6 \%$ correct). Although the HFA children's high FB scores are surprising from the standard consensus on autism, they correlate with their high correct scores in the indefinite referential condition, further emphasizing the fact that our group of children with HFA does not necessarily have a problem considering the knowledge state of the hearer, which is necessary in the application of the CNSA as well as ToM. The SLI group's relatively good performance on the FB task also correlates with their high performance on the indefinite referential condition, underscoring their low vulnerability in pragmatics. ${ }^{4}$

Our SLI results on the indefinite conditions are corroborated by Schaeffer, Hacohen \& Bernstein (2003) who conducted a spontaneous speech study on article omission and article choice in a group of 14 English-speaking children with SLI aged 3;11-4;10 and their age- and MLU-matched TD controls. None of the children with SLI (or their TD controls, for that matter) overgenerated the definite article the in indefinite contexts. These SLI results are also in line with findings 
reported by Chondrogianni \& Marinis (in press) who found very few substitutions of the indefinite with the definite article in their SLI group as well. ${ }^{5}$

Thus, overall, all groups perform target-like on both indefinite conditions, disconfirming our prediction for the HFA group that they would overgenerate the definite article the in the definite referential condition, but confirming our prediction that children with SLI older than six would NOT overgenerate the in this condition. We therefore conclude that all participants, including the children with HFA have the pragmatic Concept of Non-Shared Assumptions.

In contrast, definite articles are not always chosen in the definite condition, as illustrated in Figure 3:

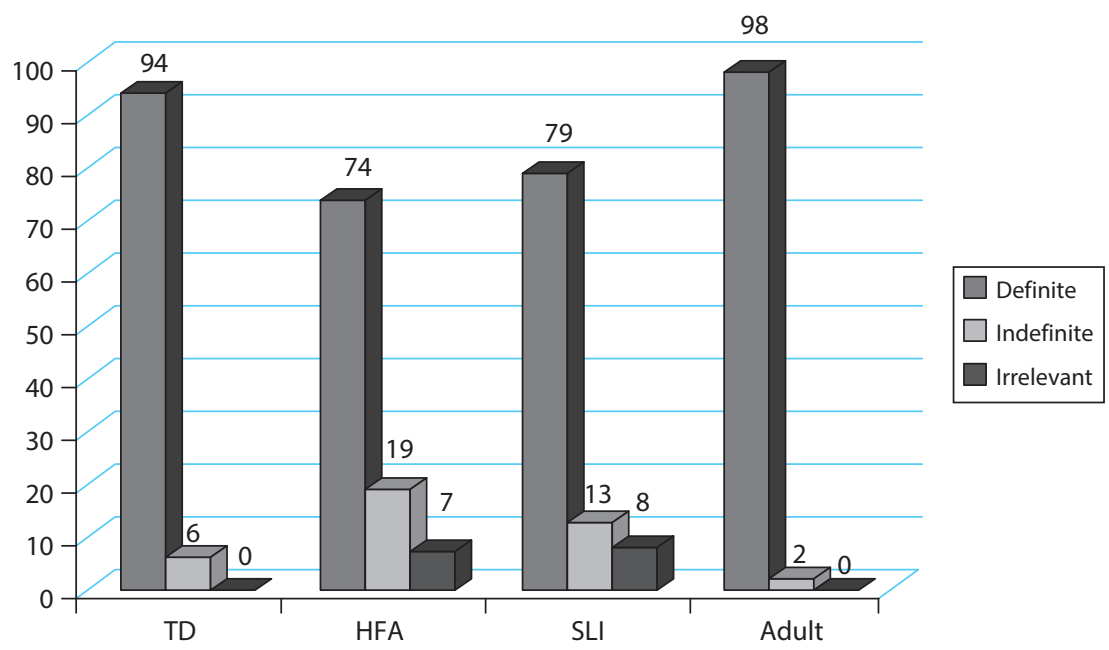

Figure 3. Definite condition: Proportions of definite (correct), indefinite (incorrect), and irrelevant responses

A Kruskall-Walis test reveals a significant difference between the number of correct definite responses of the TD, HFA and SLI groups $(\mathrm{H}(2)=7.951, p=0.019)$, with a mean rank of 24.00 for SLI, 18.31 for HFA and 31.19 for TD). Mann-Whitney U tests between the different pairs of groups show that only the difference between the HFA and the TD group is significant: The HFA group, but NOT the SLI group produces correct definite articles significantly less often than the TD group:

$$
\begin{aligned}
& \text { HFA - SLI (not significant) } \\
& \text { HFA - TD } \text { (significant, } U=57.5, p=0.004) \\
& \text { SLI - TD } \quad \text { (not significant). }
\end{aligned}
$$

The lower use of correct definite articles in the definite condition in the HFA group is largely due to the substitution of indefinite articles (19\%), confirming our second prediction. ${ }^{6}$ These indefinite article responses suggest that children with HFA 
sometimes fail to draw the scalar implicature that underlies the choice between the weaker een and the stronger de/het in a definite context. Recall from Section 2.2 that the expression een may be interpreted in two different ways: Either with an inference-driven, pragmatic reading, excluding de/het or with just its literal, semantic meaning (existence of a referent), which is also compatible with de/het. The inference-driven pragmatic reading requires the calculation of a scalar implicature. In an indefinite referential context this renders the choice for the weaker een because this choice implies that the use of the stronger de/het is too strong: This would have implied knowledge of the existence of the referent by both speaker and hearer, whereas speaker-only knowledge of the referent is appropriate in an indefinite referential context.

We propose that children with HFA are particularly prone to failing to draw scalar implicatures, following from their hypothesized pragmatic impairment. When they fail to draw the scalar implicature for definiteness, they rely on the literal, semantic meaning of (referential) een, namely the existence of a referent, which is also true for de/het. Notice that the SLI group also overgenerates een in definite contexts (13\%), but not significantly more often than their TD controls.

Because of the general heterogeneity of impaired populations, we wondered if the een-overgeneration in definite contexts was due to particular individuals. Therefore, we divided up all groups into 'passers' and 'failers'. Participants received a 'pass' if they produced 0 or 1 (out of 6) indefinite articles in the definite condition, and a 'fail' if they produced 2 or more (out of 6) indefinite articles in the definite condition. The results of this analysis are presented in (13):

(13) Individual results split up into passers and failers

\begin{tabular}{lll}
\hline & Pass & Fail \\
\hline HFA & 10 & 6 (ages: $6,6,9,9,11,11$ ) \\
SLI & 14 & 2 (ages: 8,10$)$ \\
TD & 15 & 1 (age: 9) \\
Adults & 7 & 0 \\
\hline
\end{tabular}

The division into passers and failers shows that 6 out of the 16 HFA participants (38\%) vs. a mere 2 out of 16 SLI participants (13\%) make substantial amounts of errors in the definite condition, mainly due to the substitution of the indefinite article een. This further emphasizes the pragmatic impairment (failure to draw scalar implicature) for children with HFA in particular. Nevertheless, a small subset of our children with SLI (2 so far) also displays this pragmatic impairment, suggesting that, in addition to their grammatical impairment, they may suffer from a pragmatic weakness. Future investigations of larger groups of children with HFA and with SLI should point out whether this conclusion holds. 
Zooming in on the performance of the failers in the indefinite conditions, we see that none of them ever overgenerate $d e$ in either of the indefinite conditions. Thus, we cannot speak of a general failure to consider shared knowledge, or the knowledge state of the hearer, because this would have resulted in de-overgeneration in the indefinite referential condition as well. Furthermore, the CELF scores of the failers in the HFA group is high, i.e. between 55.3 and 99.3 (mean 79.06, SD 17.08), which is above the mean of the HFA group (55.33, SD 30.44). This suggests that their lower performance on the definite condition in our experiment cannot be attributed to a morphosyntactic or lexical-semantic impairment, which is what the CELF tests. In contrast, the CELF scores of the two SLI failers are rather low (1.6 and 1.2), but this is not uncommon in the SLI group (mean 7.35, SD 7.14). The CELF mean of the other 14 SLI's (passers) is 8.2 (SD 7.26), which is far below the norm of 50 .

These more fine-grained results show that on the one hand, there are 6 children with HFA (ages: 6, 6, 9, 9, 11, 11) who perform grammatically well (see CELF scores), but have a particular problem in pragmatics, namely failing to consistently draw scalar implicatures, and, on the other hand, there are 14 children with SLI (ages $6,6,6,6,8,8,9,9,9,10,11,12,12,13$ ) who perform grammatically badly (see CELF scores), but have no problem calculating scalar implicatures. This suggests a double dissociation between grammar and pragmatics in the model of language, which can be impaired independently of each other.

Surprisingly at first sight, Chondrogianni \& Marinis (in press) report that their group of 24 English-speaking children with SLI do perform significantly worse than their TD age-matched controls on two types of definite conditions, namely an anaphoric, and a bridging condition. Most of the errors were substitutions of the indefinite article $a$ for the definite article the. This vulnerability of the definite article was also found for English-acquiring pre-school children with SLI by Polite, Leonard \& Roberts (2011). However, further analysis shows that only $25 \%$ of the children with SLI in Chondrogianni \& Marinis' study do this at a substantial rate (= more than $50 \%$ of the time). In our view, this small subset of Chondrogianni \& Marinis' children with SLI may have an additional pragmatic impairment, namely, the failure to draw a scalar implicature, as we suggested for the 2 children with SLI in our own study.

Although the wide age range of the failers in both groups suggests that correct $d e$-use in the definite condition does not necessarily develop by age, we did a more detailed investigation into potential development by dividing the TD, HFA, and SLI groups into three age groups: Age 5-8 years, age 9-10, and age 11-13. The results are presented in Figures 4 and 5: 


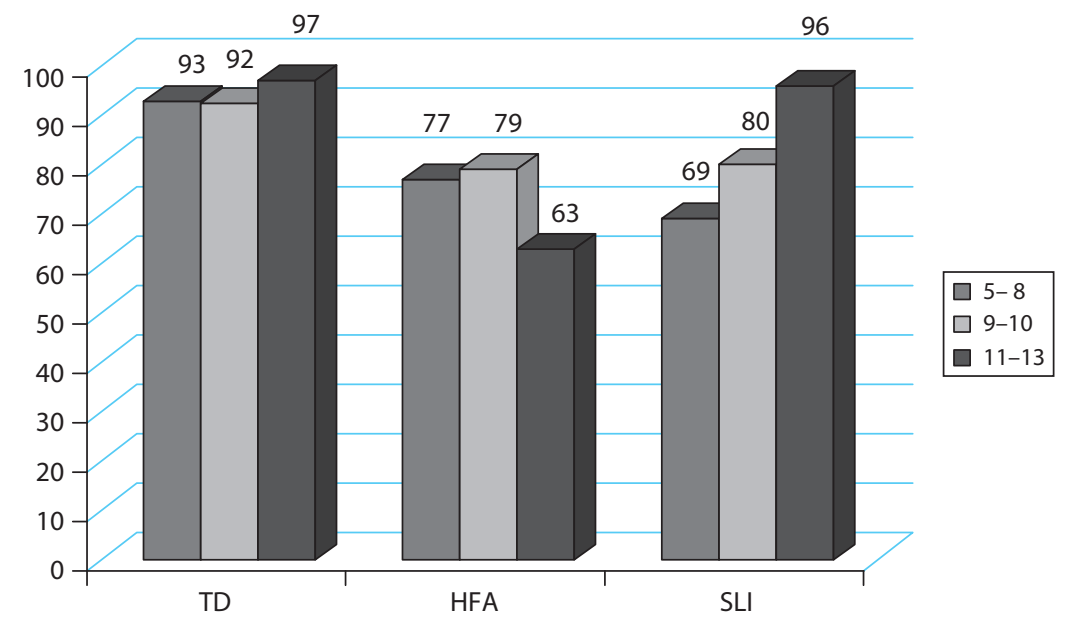

Figure 4. Definite condition: Proportions of definite (correct) responses per age group

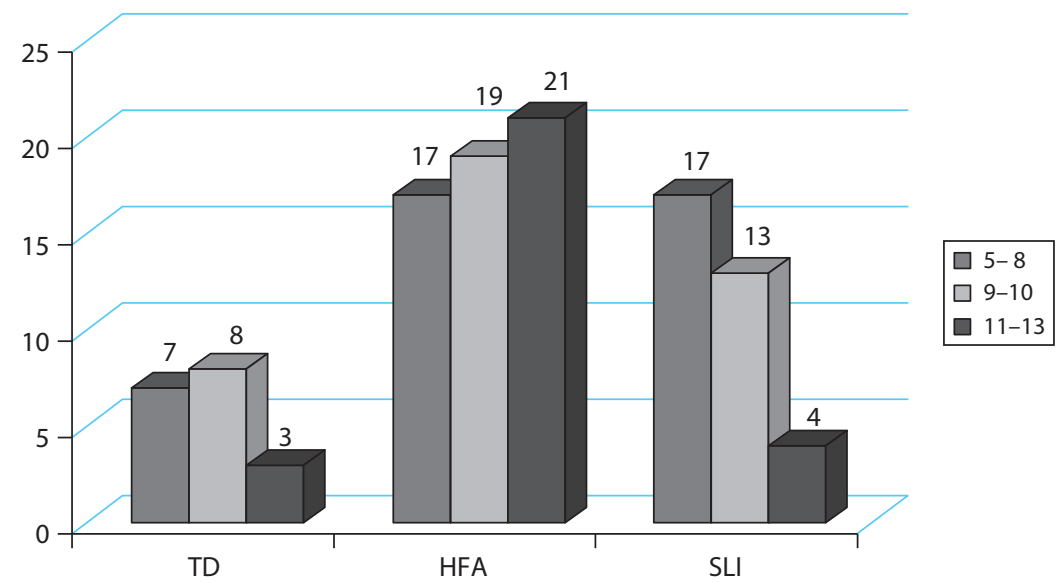

Figure 5. Definite condition: Proportions of indefinite (incorrect) responses per age group

Interestingly, the children with SLI show clear development towards TD/ adultlike production of definite articles in definite contexts, while the children with HFA do not; in fact, the older children with HFA overgenerate the indefinite article $a$ in definite contexts even more often than the younger children with HFA. This provides further evidence for the hypothesis that (some) children with HFA have a persistent pragmatic impairment, while (some) children with SLI may be pragmatically delayed somewhat, but overcome this problem when they grow older. The error percentages for the TD group are too low to speak of real development, although they do demonstrate that the oldest TD children perform best. 


\section{Conclusion}

In this study, we examined the choice between a definite and an indefinite article in two impaired Dutch-speaking child populations aged 6-13, namely nongrammatically impaired High Functioning Autism (HFA) and Specific Language Impairment (SLI) by means of an Elicited Production Task. We show that all children make virtually no substitution errors in any of the indefinite conditions, disconfirming our hypothesis that children with HFA lack the pragmatic Concept of Non-Shared Assumptions. However, children with HFA, but NOT children with SLI, produce correct definite articles in definite contexts significantly less often than their TD peers. This is due mainly to the incorrect substitution of indefinite articles in these contexts. Arguing that this error results from the failure to draw a (pragmatic) scalar implicature, we take this to be evidence for the hypothesis that non-grammatically impaired children with HFA are more prone to pragmatic impairments than children with SLI. This suggests a dissociation between grammar and pragmatics as separate components of language, although larger groups and more grammatical and pragmatic phenomena should be examined.

\section{Notes}

1. Notice that the absence of the CNSA causes the grouping together of environments A and B, as opposed to $\mathrm{C}$, rendering overgeneration of the in indefinite referential contexts, but crucially NOT overgeneration of een in definite contexts.

2. The pragmatic abilities examined in the CCC include 1. Inappropriate initiation, 2. Stereotypical language, 3 . Use of context, and 4. Non-verbal communication.

3. For reasons that go beyond the purpose of this paper we included twice as many test items for the indefinite conditions as compared to the definite condition. In the indefinite-non-referential condition we had to exclude 2 test items because of severe item effects which were also visible in the adult results.

4. Of course it is surprising that both our impaired groups perform better on the FB task than their TD age-mates. Although this particular difference is not very relevant for the current study, we will further investigate it. The difference may disappear when we investigate larger groups.

5. As Figure 1 shows, irrelevant responses occur more often in the indefinite non-referential condition than in the indefinite referential condition (Figure 2). These irrelevant responses mainly include responses in which no article is produced (Big Bird is going to draw something), and some responses involving numerals (Nijntje baked one cake). We believe that this is due to the nature of the particular task in this condition: The participant has to come up with a completely new, still non-existing referent, which is cognitively more demanding (especially for children) than relating to an already existing referent. 
6. As Figure 3 shows, the HFA and SLI groups also show some irrelevant responses. These responses consisted mainly of demonstratives (Hij zit te knuffelen met die hond. 'He is cuddling with that dog') and some article omissions (Hij knuffelde knuffelbeer. 'He cuddled teddybear).

7. Interestingly, one 9-year-old TD child also produced 3 indefinites in the definite condition. This child's CELF score was normal (76.80), as compared to the other children in the TD group (mean 78.04), and no de-overgeneration was found in either of the indefinite conditions. At this point, we have no explanation for this TD child's bad performance on the definite condition. In future analyses of other test scores we will pay extra attention to this TD child.

\section{References}

Abbott, Barbara. 1999. Support for a unique theory of definiteness. In Tanya Matthews \& Devon Strolovitch (eds.), Proceedings from Semantics and Linguistic Theory (SALT) 9, 1-15. Ithaca, NY: CLC Publications.

Abbott, Barbara. 2003. A reply to Szabó's "Descriptions and uniqueness". Philosophical Studies 113(3). 223-231. DOI: 10.1023/A:1024063903859

Baron-Cohen, Simon. 1988. Social and pragmatic deficits in autism: Cognitive or affective? Journal of Autism and Developmental Disorders 18(3). 379-402. DOI: 10.1007/BF02212194

Bishop, Dorothy V. M. 1997. Uncommon understanding: Development and disorders of language comprehension in children. Hove, UK: Psychology Press.

Boucher, Jill. 2009. The autistic spectrum: Characteristics, causes and practical issues. Thousand Oaks, CA: Sage.

Carston, Robyn. 1998. Informativeness, relevance and scalar implicature. In Robyn Carston \& Sachico Uschida (eds.), Relevance Theory: Applications and Implications, 79-236. Amsterdam: John Benjamins.

Chierchia, Gennaro. 2004. Scalar implicatures, polarity phenomena, and the syntax/pragmatics interface. Structures and Beyond 3. 39-103.

Chondrogianni, Vicky \& Theo Marinis. In press. Production of definite and indefinite articles in typically developing English-speaking children and children with SLI. Lingua: Special Issue on the Acquisition of Reference and Referentiality.

Colle, Livia, Simon Baron-Cohen \& Jaqueline Hill. 2007. Do children with autism have a theory of mind? A non-verbal test of autism vs. specific language impairment. Journal of Autism and Developmental Disorders 37(4). 716-723. DOI: 10.1007/s10803-006-0198-7

Crain, Stephen \& Rosalind Thornton. 2000. Investigations in universal grammar: A guide to experiments on the acquisition of syntax and semantics. Cambridge: MIT Press.

Eigsti, Inge-Marie, Ashley B. de Marchena, Jillin M. Schuh \& Elizabeth Kelley. 2011. Language acquisition in autism spectrum disorders: A developmental review. Research in Autism Spectrum Disorders 5(2). 681-691. DOI: 10.1016/j.rasd.2010.09.001

Friedmann, Naama \& Rama Novogrodsky. 2008. Subtypes of SLI: SySLI, PhoSLI, LeSLI, and PraSLI. In Anna Gavarró \& Maria João Freitas (eds), Language Acquisition and Development, 205-217. Newcastle, UK: Cambridge Scholars Press/CSP. 
Friedmann, Naama \& Rama Novogrodsky. 2011. Which questions are most difficult to understand? The comprehension of Wh-questions in three subtypes of SLI. Lingua 121(3). 367382. DOI: $10.1016 /$ j.lingua.2010.10.004

Frith, Uta. 1989. Autism: Explaining the enigma. British Journal of Developmental Psychology 3. 465-468.

Geurts, Hilde M. 2007. CCC-2-NL: Children's Communication Checklist-2. Amsterdam: Harcourt Assessment B.V.

Gordishevsky, Galina \& Sergey Avrutin. 2004. Optional omissions in an optionally null subject language. In Jaqueline van Kampen \& Sergio Baauw (eds.), Proceedings of GALA 2003, Vol. 1, 187-198. Utrecht University: LOT Occasional series 3.

Hawkins, John A. 1991. On (in)definite articles: Implicatures and (un)grammaticality prediction. Journal of Linguistics 27. 405-442. DOI: 10.1017/S0022226700012731

Heim, Irene 1982. The semantics of definite and indefinite NPs. Ph.D. Dissertation, University of Massachusetts, Amherst: GLSA.

Hendriks, Petra, Helen de Hoop, Irene Krämer, Henriëtte E. de Swart \& Joost Zwarts. 2010. Conflicts in Interpretation (Advances in Optimality Theory). London: Equinox Publishing.

Henry, Lucy A., David J. Messer \& Gilly Nash. 2012. Executive functioning in children with specific language impairment. Journal of Child Psychology and Psychiatry 53(1). 37-45.

DOI: $10.1111 / \mathrm{j} .1469-7610.2011 .02430 . \mathrm{x}$

Horn, Laurence R. 1989. A natural history of negation. Chicago: University of Chicago Press.

Horn, Laurence R. 2006. Toward a Fregean pragmatics: Voraussetzung, Nebengedanke, Andeutung. In Laurence R. Horn \& Istvan Kecskes (eds.), Explorations in Pragmatics: Linguistic, Cognitive, and Intercultural Aspects, 39-69. Berlin: Mouton.

Van Hout, Angeliek, Kaitlyn Harrigan, \& Jill de Villiers. 2010. Asymmetries in the acquisition of definite and indefinite NPs. Lingua 120(8). 1973-1990. DOI: 10.1016/j.lingua.2010.02.006

Ionin, Tania R. \& Kenneth N. Wexler. 2003. The certain uses of the in L2-English. In Juana. M. Liceras, Helmut Zobl \& Helen Goodluck (eds.), Proceedings of the 6 th Generative Approaches to Second Language Acquisition Conference, 150-160. Somerville: Cascadilla Press.

Ionin, Tania, Heejeong Ko \& Kenneth Wexler. 2004. Article semantics in L2 acquisition: The role of specificity. Language Acquisition 12(1). 3-69. DOI: 10.1207/s15327817la1201_2

Ionin, Tania, Maria L. Zubizarreta \& Salvador B. Maldonado. 2008. Sources of linguistic knowledge in the second language acquisition of English articles. Lingua 118(4). 554-576.

DOI: $10.1016 /$ j.lingua.2006.11.012

Karmiloff-Smith, Annette. 1979. A functional approach to child language. Cambridge: Cambridge University Press.

Van der Lely, Heather K.J. 1998. SLI in children: Movement, economy and deficits in the computational-syntactic system. Language Acquisition 7. 161-192.

DOI: $10.1207 /$ s15327817la0702-4_4

Van der Lely, Heather K. J. \& Linda Stollwerck. 1997. Binding theory and grammatical specific language impairment in children. Cognition 62(3). 245-290.

DOI: 10.1016/S0010-0277(96)00783-4

Leonard, Laurence B. 1998. Children with specific language impairment. Cambridge, MA: MIT Press.

Levinson, Stephen. 2000. Presumptive meanings: The theory of generalized conversational implicature. Cambridge, MA: MIT Press. 
Loukusa, Soile \& Irma Moilanen. 2009. Pragmatic inference abilities in individuals with Asperger syndrome or high-functioning autism. A review. Research in Autism Spectrum Disorders 3(4). 890-904. DOI: 10.1016/j.rasd.2009.05.002

Maratsos, Michael. P. 1976. The use of definite and indefinite reference in young children: An experimental study of semantic acquisition. Cambridge: Cambridge University Press.

Perovic, Alexandra, Nadya Modyanova \& Kenneth Wexler. 2013a. Comprehension of reflexive and personal pronouns in children with autism: A syntactic or pragmatic deficit? Applied Psycholinguistics 34(4). 813-835. DOI: 10.1017/S0142716412000033

Perovic, Alexandra, Nadya Modyanova \& Kenneth Wexler. 2013b. Comparison of grammar in neurodevelopmental disorders: The case of binding in Williams syndrome and autism with and without language impairment. Language Acquisition 20(2). 133-154.

DOI: 10.1080/10489223.2013.766742

Polite, Elgustus J., Laurence B. Leonard \& Felicia D. Roberts. 2011. The use of definite and indefinite articles by children with specific language impairment. International Journal of Speech-Language Pathology 13. 291-300. DOI: 10.3109/17549507.2011.558116

Pouscoulous, Nausicaa, Ira A. Noveck, Guy Politzer \& Anne Bastide. 2007. A developmental investigation of processing costs in implicature production. Language Acquisition 14(4). 347-375. DOI: 10.1080/10489220701600457

Premack, David \& Guy Woodruff. 1978. Does the chimpanzee have a 'theory of mind'? Behavioral and Brain Sciences 4. 515-526. DOI: 10.1017/S0140525X00076512

Rice, Mabel L. 1996. Toward a genetics of a language. Mahwah, NJ: Lawrence Erlbaum.

Rispens, Judith \& Anne Baker 2012. Nonword repetition: The relative contributions of phonological short-term memory and phonological representations in children with language and hearing impairment. Journal of Speech, Language and Hearing Research 55(3). 683-694. DOI: 10.1044/1092-4388(2011/10-0263)

Russell, Bertrand. 1905. On denoting. Mind 14. 479-493. Reference is to the reprint in Al P. Martinich (ed.), 1996. The Philosophy of Language, 1996. Third edition, 199-207. New York: Oxford University Press. DOI: 10.1093/mind/XIV.4.479

Schaeffer, Jeannette, Aviya Hacohen \& Arielle Bernstein. 2003. On the acquisition of DP in English-speaking children with SLI. In Barbara Beachley, Amanda Brown, Frances Colin (eds.), Proceedings of the 27th Boston University Conference on Language Development 2, 716-726. Somerville, MA: Cascadilla Press.

Schaeffer, Jeannette \& Lisa Matthewson. 2005. Grammar and pragmatics in the acquisition of article systems. Natural Language \& Linguistic Theory 23(1). 53-101.

DOI: 10.1007/s11049-004-5540-1

Schafer, Robin J. \& Jill de Villiers. 2000. Imagining articles: What $a$ and the can tell us about the emergence of DP. In S. Catherine Howell, Sarah A. Fish, Thea Keith-Lucas (eds.), Proceedings of the 24th annual Boston University Conference on Language Development 2, 609-620. Somerville, MA: Cascadilla Press.

Semel, Eleanor M., Elisabeth H. Wiig, Wayne A. Secord \& Willem Kort. 2008. CELF 4 NL: Clinical evaluation of language fundamentals: Nederlandse versie. Pearson.

Stalnaker, Robert 1974. Pragmatic presuppositions. In Milton K. Munitz \& Peter Unger (eds.), Semantics and Philosophy, 197-214. New York: New York University Press.

Stalnaker, Robert 1978. Assertion. In Peter Cole (eds.), Syntax and Semantics 9: Pragmatics, 313-332. New York: Academic Press. 
Tager-Flusberg, Helen. 1989. A psycholinguistic perspective on language development in the autistic child. In Geraldine Dawson (ed.), Autism: Nature, diagnosis, and treatment, 92-115. New York: Guilford Press.

Tallal, Paula, Randal Ross \& Susan Curtiss. 1989. Unexpected sex-ratios in families of language/ learning-impaired children. Neuropsychologia 27. 987-998.

DOI: 10.1016/0028-3932(89)90074-2

Taylor, Julie L., Melissa L. McPheeters, Nila A. Sathe, Dwayne Dove, Jeremy Veenstra-Van der Weele \& Zachary Warren. 2012. A systematic review of vocational interventions for young adults with autism spectrum disorders. Pediatrics 130(3). 531-538.

DOI: $10.1542 /$ peds.2012-0682

Tomblin, Bruce 1989. Familial concentration of developmental language impairment. Journal of Speech and Hearing Disorders 54. 287-295.

Westergaard, Marit R. 2008. Verb movement and subject placement in the acquisition of word order: Pragmatics or structural economy? In Pedro Guijarro-Fuentes, María P. Larranaga \& John. Clibbens (eds.), First Language Acquisition of Morphology and Syntax, 61-86. Amsterdam: John Benjamins. DOI: 10.1075/lald.45.03wes

Wilson, Dan \& Deirdre Sperber. 2004. Experimental pragmatics. In Frank Jackson \& Michael Smith (eds.), Handbook of Contemporary Analytical Philosophy, 607-632. Oxford: Blackwell.

Zehler, Annette M. \& William F. Brewer. 1982. Sequence and principles in article system use: An examination of $a$, the, and null acquisition. Child Development 53. 1268-1274.

Zdorenko, Tatiana \& Johanne Paradis. 2008. The acquisition of articles in child second language English: Fluctuation, transfer or both? Second Language Research 24(2). 227-250.

DOI: $10.1177 / 0267658307086302$

\section{Author's address}

Jeannette Schaeffer

Department of Dutch Linguistics

University of Amsterdam

Spuistraat 134

1012 VB Amsterdam, The Netherlands

j.c.schaeffer@uva.nl 